\title{
Phototoxicity in a laryngeal cancer cell line enhanced by a targeting amphiphilic chlorin photosensitizer
}

\author{
Milene N.O. Moritz ${ }^{\mathrm{a}}$, Carlos Rossa Junior ${ }^{\mathrm{b}}$, Kleber T. de Oliveira ${ }^{\mathrm{c}}$, Marciana P. Uliana ${ }^{\mathrm{c}}$, \\ Janice R. Perussi ${ }^{\mathrm{a}, \mathrm{d}, *}$ \\ a Programa de Pós-Graduação Interunidades Bioengenharia EESC/FMRP/IQSC, Universidade de São Paulo, São Carlos, SP, Brazil \\ b Departamento de Diagnóstico e Cirurgia, Universidade Estadual Paulista Júlio de Mesquita Filho, Araraquara, SP, Brazil \\ c Departamento de Química, Universidade Federal de São Carlos, São Carlos, SP, Brazil \\ d Instituto de Química de São Carlos, Universidade de São Paulo, São Carlos, SP, Brazil
}

\section{A R T I C L E I N F O}

\section{Keywords:}

Amphiphilic chlorin

Photodynamic therapy

Tumor cells

Phototoxicity

Apoptosis

p-53

\begin{abstract}
A B S T R A C T
Background: Photodynamic therapy (PDT) has been established in several countries as an alternative therapy for the treatment of various malignancies. This therapy involves the incorporation of a photosensitizer (PS) that is activated by visible light and form reactive oxygen species leading to target cell death by apoptosis or necrosis. Previously, our group has demonstrated that CHL-T (semi-synthesized from chlorophyll $a$ and containing a linked solubilizing group TRISMA ${ }^{\circ}$ ) presented a pronounced potential to induce death in HeLa cell line after PDT. In the present study, besides confirm the high cytotoxicity in another cell line, we have further investigated the cell death mechanisms caused by CHL-T as a photosensitizer in laryngeal carcinoma cells.

Methods: Cells were exposed to different concentrations of three photosensitizers, namely, hypericin (HY), unmodified chlorin (CHL) and a synthesized amphiphilic chlorin derivative (CHL-T). PSs accumulation and localization were accessed by fluorescence assays. Photosensitization was induced at $6 \mathrm{~J} \mathrm{~cm}^{-2}$ using red LEDs $(630 \pm 10 \mathrm{~nm})$. Viability was assessed by mitochondrial function (MTT); whereas apoptosis/necrosis was evaluated by fluorescence microscopy and flow cytometry. Expression of pro-apoptotic p53 protein was studied by Western blot.

Results and conclusions: All PS showed similar localization profile in the HEp-2 cells. The use of CHL-T increased the percentage of apoptotic cells and also p53 expression in comparison with the use of HY and CHL as photosensitizers. This study shows a significant effect of CHLT associated with red light $(630 \pm 10 \mathrm{~nm}$ and $18 \mathrm{~mW} \mathrm{~cm}^{-2}$ ) irradiation on a cancer cell line, indicating the potential of this amphiphilic chlorin in enhancing the therapeutic effectiveness of Photodynamic Therapy (PDT).
\end{abstract}

\section{Introduction}

Photodynamic therapy (PDT) is a modality of cellular or microorganism damage which allows for a greater selectivity of the treated area, since the light stimulus and its biological effects can be precisely directed and restricted to the targeted tissue/area [1,2]. PDT involves the incorporation of a photosensitizer (PS), a chemical compound that is activated by visible light in the presence of oxygen leading to formation of Reactive Oxygen Species (ROS), and consequently to tumor cell death [2,3]. However, to establish PDT as a mainstream therapeutic option, some limitations have to be eliminated [4].

New photosensitizers (PSs) have been developed in order to overcome limitations such as the prolonged photosensitivity caused by porphyrins, as well as to absorb light at longer wavelengths [5]. Importantly, the amphiphilic character of a PS is crucial both for its transport in the blood stream and for its entry into the cells with their lipid-containing plasma membrane [6,7].

Chlorins and hypericin are PSs, characterized by absorption at longer wavelengths, shorter periods of photosensitivity and higher production of singlet oxygen in comparison with porphyrins. However, many chlorin derivatives and hypericin are poorly soluble in waterbased vehicles and have high tendency for aggregation as well, which limit their use in PDT [8]. To overcome these mentioned inefficiencies, modified chlorin derivatives have been synthesized achieving a number of physico-chemical properties more suitable for PDT treatments [9-12].

\footnotetext{
* Corresponding author at: Departamento de Química e Física Molecular, Instituto de Química de São Carlos, Universidade de São Paulo, Av. Trabalhador São Carlense, 400, 13566 - 590 São Carlos, SP, Brazil.

E-mail address: janice@iqsc.usp.br (J.R. Perussi).
} 
Intrinsic regulatory pathways of cell survival and death are rigorously controlled, and identifying which pathways are involved in mediating the survival of cancer cells may have therapeutic implications [13]. The p53 protein plays an important role in regulating apoptosis, cell cycle, cell senescence and DNA repair. Upon a stress signal, p53 is translocated to the mitochondria and interacts with the Bcl-2 family proteins, triggering the caspase cascade and chromatin condensation, which are initial events leading to apoptosis [14].

There is much interest in identifying the molecular mechanisms associated with PDT-induced cell death, as this understanding can enable the use of novel strategies improving the efficiency of PDT $[15,16]$. In the present study, methylpheophorbide $a$ (CHL) was semi-synthesized from chlorophyll $a$, and a amphiphilic chlorin derivative (CHL-T) obtained from (CHL) after transamidation reaction with TRISMA ${ }^{\circ}(2$ amino-2-(hydroxymethyl)propane-1,3-diol) [17]. That previous paper from our group indicated that this chemical modification activated cell death in cervical tumor cells in low concentrations, whereas a nonneoplasic cell line was affected only at higher concentrations, demonstrating selectivity for neoplasic cells. Therefore, the aim of the present study was characterize the cytotoxic effects and to elucidate the molecular mechanisms in HEp-2 cell line of CHL-T in comparison with CHL and with another well-studied photosensitizer, hypericin.

\section{Materials and methods}

\subsection{Cell culture}

Human laryngeal carcinoma cells (HEp-2 ATCC ${ }^{\bullet}$ CCL-23 ${ }_{\mathrm{TM}}$ ) were obtained from Adolfo Lutz Institute (São Paulo-SP, Brazil). Cells were cultured in Iscove's medium supplemented with $10 \%$ fetal bovine serum and $0.01 \%$ of antibiotics (penicillin and streptomycin) at $37^{\circ} \mathrm{C}$ and $5 \%$ $\mathrm{CO}_{2}$. For all experiments the minimum cell viability considered for plating was $90 \%$, using the trypan blue test.

\subsection{Photosensitizers (PSs)}

The hypericin (HY) was synthetized by Dr. Anderson O. Ribeiro from Center of Natural Sciences and Humanities of Federal University of ABC (Santo Andre, SP, Brazil) according to described protocols [18] and chlorin derivatives (CHL and CHL-T) were synthetized by Dr. Kleber T. Oliveira [17] from Chemistry Department of Federal University of Sao Carlos (Sao Carlos, SP, Brazil). The stock solutions were prepared in dimethyl sulfoxide (DMSO) at $1000 \mu \mathrm{gL}^{-1}$, sonicated, sterilized by filtering through a $0.22 \mu \mathrm{m}$ pore membrane and stored at $4{ }^{\circ} \mathrm{C}$ with protection from light. The absorption spectra are presented in Fig. 1. The molar absorption coefficients are $2.29 \times 10^{4}, 5.51 \times 10^{4}$ and $2.16 \times 10^{4} \mathrm{M}^{-1} \mathrm{~cm}^{-1}$ respectively to $\mathrm{CHL}(667 \mathrm{~nm})$, CHL-T $(670 \mathrm{~nm})$ and $\mathrm{HY}(599 \mathrm{~nm})$.

\subsection{Intracellular accumulation of photosensitizers}

Fluorescence emission was used to determine the amount of PSs incorporated by the cells after $1 ; 2 ; 4 ; 8 ; 16$ and $24 \mathrm{~h}$ of incubation with the PSs after the lysing of the cells with ethanol. First, $10^{5}$ cells were seeded in $6 \mathrm{~cm}$ plate dishes and after $24 \mathrm{~h}$ the photosensitizers were incubated during the different periods mentioned above. Then, cells were lysed with ethanol, centrifuged and PSs in the supernatant were measured by fluorescence. The fluorescence intensities were normalized by the protein concentration of each sample obtained according to the Lowry method using the Folin reagent [19]. Analytical curves of each tested PS were previously obtained in ethanol. Fluorescence measurements were performed in a spectrofluorimeter (HITACHI F4500, Japan). Data were analyzed in OriginPro 8 program.

\subsection{Intracellular localization of photosensitizers}

Fluorescence images were accessed by fluorescence microscopy to determine the PSs localizations. The cells were plated $\left(10^{4}\right.$ cells per well) in a 96 well black plate (greiner) and incubated overnight. After, the PSs (CHL, CHL-T and HY) were added at $5 \mu \mathrm{M}$ and incubated for $1 \mathrm{~h}$. Then, the cells were washed twice with PBS, fixed with $4 \%$ formaldehyde and the nuclei were stained with $2.5 \%$ DAPI (4'-6Diamidino-2 Phenilidol). The images were acquired by automated fluorescence microscopy with the Digital Confocal Option at MetaXpress software (ImageXpress", Molecular Device) at a $600 \times$ magnification. The PSs were excited at $628 / 40 \mathrm{~nm}$ and detected at $692 /$ $40 \mathrm{~nm}$; DAPI fluorescence were excited at $374 / 50 \mathrm{~nm}$ and detected at $447 / 60 \mathrm{~nm}$.

\subsection{Irradiation conditions}

For all cellular assays was used an illumination table (Biotable, LATCEPOF, Sao Carlos, Brazil) containing a matrix of $5 \times 10$ LEDs emitting red light $(630 \pm 10 \mathrm{~nm})$ at an irradiance of $18 \mathrm{~mW} \mathrm{~cm}^{-2}$. The total light dose used was $16 \mathrm{~J} \mathrm{~cm}^{-2}$ and corresponds to $13 \mathrm{~min}$ and $51 \mathrm{~s}$.

\subsection{Cell photosensibilization}

For photodynamic assays, cells were initially incubated with different concentrations of CHL, CHL-T or HY for $2 \mathrm{~h}$ and $16 \mathrm{~h}$ to allow the cellular uptaking of the PSs. For the cytotoxic assays, $2 \times 10^{4}$ cells $\mathrm{mL}^{-1}$ were seeded in 96 -well plates with $200 \mu \mathrm{L}$ of medium per well.

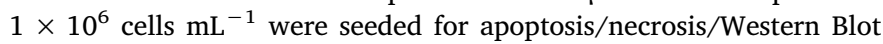
assays in 6-well plates with $2 \mathrm{~mL}$ of Iscove's Modified Dulbecco's medium supplemented with $10 \% \mathrm{FBS}$ and grown at $37^{\circ} \mathrm{C}$ and $5 \% \mathrm{CO}_{2}$.

\subsection{MTT cell viability assay}

A total of $2 \times 10^{4}$ cells per well were plated in each well of 96-well plates. After $24 \mathrm{~h}$, the different PSs were added at the indicated concentrations in culture medium for 2 or $16 \mathrm{~h}$ (predetermined by the accumulation assay). Then, the cells were washed with PBS and irradiated. Twenty-four $h$ post irradiation, MTT was added to each well and after $4 \mathrm{~h}$ the formazan crystals formed were solubilized with $50 \mu \mathrm{L}$ of absolute ethanol and $150 \mu \mathrm{L}$ of isopropyl alcohol. Absorbance at $570 \mathrm{~nm}$ were determined using an absorbance microplate reader (VersaMax, Molecular Devices) and the median inhibitory concentrations $\left(\mathrm{IC}_{50}\right.$ ) calculated using the program CalcuSyn [20]. Controls included untreated cells; cells treated with PSs but not irradiated; and cells that were irradiated in the absence of PSs. Three independent assays with sextuplicates were performed.

\subsection{Cell death assays}

Cell death (apoptosis and necrosis) induced by photodynamic process was evaluated by fluorescence microscopy and flow cytometry. For fluorescence microscopy, cells were stained with ethidium bromide and acridine orange [21]. Visualization was performed with a fluorescence microscope (Olympus BX41), at $200 \times$ magnification, excitation filter at $460 / 90 \mathrm{~nm}, 500 \mathrm{~nm}$ dichromatic mirror and $520 \mathrm{~nm}$ barrier filter. A trained operator unaware of the experimental conditions counted 200 cells in random fields of each well to calculate the percentage of cell death. Two independent assays with triplicates were performed.

Apoptosis was assessed by flow cytometry using a commercially available kit (FITC-Annexin V Apoptosis Detection Kit, BD Biosciences), according to the manufacturer's instructions and the data was acquired on a FACS Verse (BD Biosciences) cytometer. Cells were plated $\left(1 \times 10^{6}\right.$ cells/well) in 6-well plates. After $24 \mathrm{~h}$, PSs were incubated at $0.52 \mu \mathrm{M}$ during $2 \mathrm{~h}$. This pre-incubation time was chosen once cellular accumulation was similar for both chlorin derivatives at the mentioned 
A

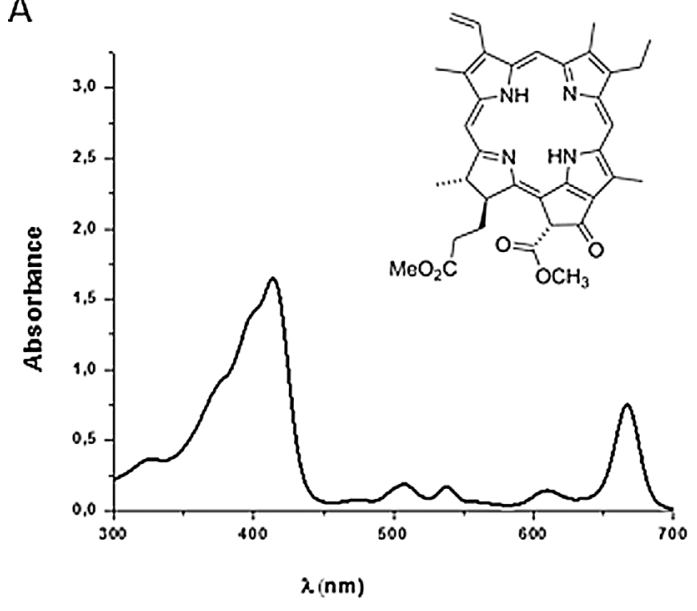

B

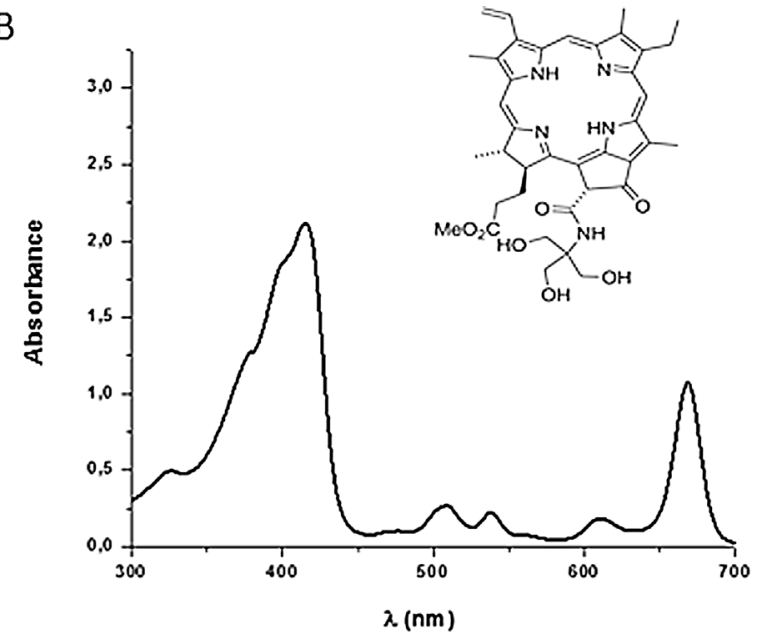

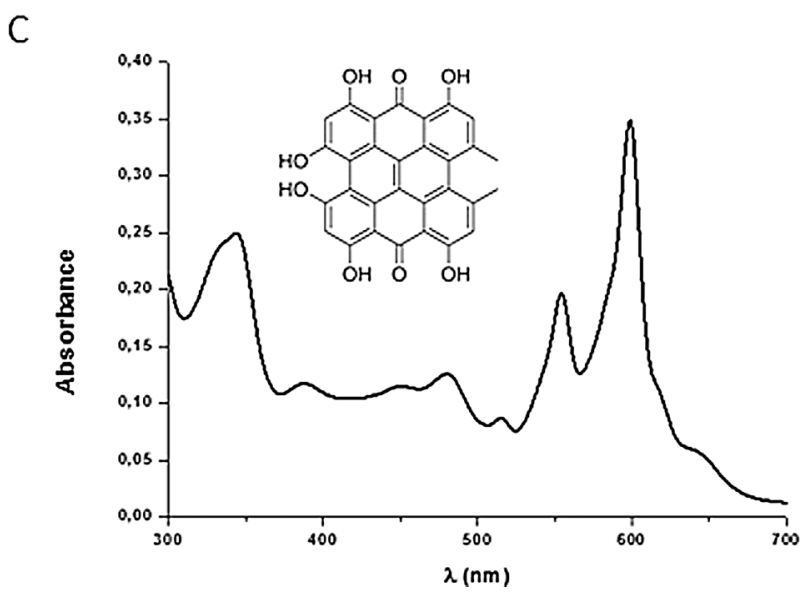

Fig. 1. Absorption spectra of $2 \times 10^{-5} \mathrm{M}$ PS solutions in DMSO. A: CHL; B: CHL-T; C: HY.

condition. Cells were washed with PBS and irradiated. After an additional $24 \mathrm{~h}$ cells were detached from the plates, combined with unattached cells suspended in the culture medium and stained with Annexin V-FITC and PI. A minimum of 10,000 events acquired in two independent experiments with triplicates were considered for the analysis of the results.

For both cell death assays, controls were included: untreated cells; cells treated with PSs but not irradiated; and cells irradiated in the absence of PSs. In the flow cytometry experiment, the gating strategy initially excluded cell debris (on a FSC-SCC dot-blot), generating 'P1' and subsequently the cell doublets were excluded on two dot-blots: FSC-Area x FSC-Width and SSC-Area x SSC-Width. These dot-blots generated P2 (considering only 'P1' events, i.e., cells minus cell debris and excluding cell doublets) and P3 (considering only 'P2' events, i.e., cells and a 'second pass' to exclude cell doublets). A fourth dot plot (considering only 'P3' events) was set up with the parameters FITC $\mathrm{x}$ PE to identify fluorescence signals emitted by Annexin V-FITC and propidium iodide (PI) after excitation with the $488 \mathrm{~nm}$ laser. Compensation for the spectral overlap between fluorescence detection in FL1 (FITC) and FL2 (PE) channels was based on the experimental controls and adjusted after data acquisition using the median fluorescence intensity of positives in the negative channel.

\section{9. p53 protein expression}

Effect of PDT on p53 protein expression was assessed by Western blot. Briefly, $1 \times 10^{6}$ cells were plated in each well of 6-well plates. After $24 \mathrm{~h}$, the PSs were incubated at a concentration of $0.52 \mu \mathrm{M}$ during
$2 \mathrm{~h}$ (standardized conditions). Then, the cells were washed with PBS and irradiated. After $24 \mathrm{~h}$, total cell lysates were collected under nondenaturing conditions using a Tris-Cl, Triton-X-based lysis buffer (Cell lysis buffer, Cell Signaling) supplemented with a cocktail of protease inhibitors (Complete EDTA-free, Santa Cruz). Protein quantitation was carried out using the Bradford method, according to the supplier's instructions (Bio-Rad Lab). $40 \mu \mathrm{g}$ of each sample were diluted in a denaturing sample buffer containing glycerol, SDS, DTT and bromophenol blue. A mouse monoclonal antibody for p53 (cat\# ab26, Abcam) was used at 1:4000 dilution. Loading control was assessed by detecting GAPDH with a rabbit monoclonal antibody (cat\# 2118, Cell Signaling) at 1:1000 dilution. Detection of proteins was performed by incubating the membranes with species-specific secondary antibodies conjugated to HRP and a chemiluminescence system (Super Signal West Pico Chemiluminescent Substrate - Thermo Scientific/Pierce). Images were obtained on a digital documentation system (Chemi-Doc Xr, Bio Rad Lab) and relative quantitation was done by densitometric analysis of the images using the Image $J$ software and normalizing to GAPDH band densities. Two independent experiments were carried out and the samples were performed twice to the Western blot analysis.

\subsection{Statistical analysis}

The purpose of data analysis was to compare the results of interest among the different PSs used. In general, when data distribution was near-normal we used ANOVA followed by post-hoc Tukey for multiple comparisons, unless otherwise indicated. All analysis was performed using GraphPad 5.0 software with significance level set to $5 \%$. 


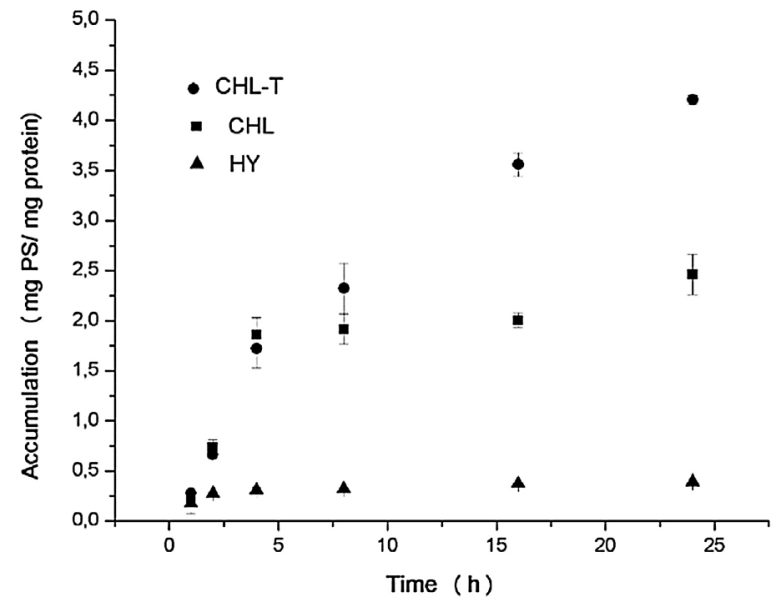

Fig. 2. Intracellular accumulation (PS $\mathrm{mg} / \mathrm{mg}$ cell protein) of photosensitizers at concentration of $1.4 \times 10^{-6} \mathrm{M}$ in HEp- 2 cells as a function of incubation time, $n=3$.

\section{Results}

\subsection{Intracellular accumulation of photosensitizers}

Cell lysates prepared at different time points were used to determine the accumulation of the different PSs by quantitating the fluorescence emitted, which was directly proportional to the quantity of PSs in the cytosol. The data for intracellular PS accumulation over time is shown in Fig. 2.

Intracellular accumulation of both (CHL and CHL-T) was markedly greater than for hypericin after $2 \mathrm{~h}$ of incubation. At the same concentration, accumulation of the modified chlorin (CHL-T) was clearly greater than for CHL after 16 and $24 \mathrm{~h}$ of incubation.

\subsection{Photosensitizers localization assay}

The localization of each PS (CHL, CHL-T and HY) are shown in Fig. 3. The PSs are perinuclear located (indicated by arrows) in the cytoplasm and their distribution appears similar comparing each one.

\subsection{MTT cell viability assay}

The effects of CHL, CHL-T and HY on cell viability are indicated as the relative percentages of cell viability in comparison to the corresponding control. To determine the mean inhibitory concentration $\left(\mathrm{IC}_{50}\right)$ of the PSs at the defined irradiation conditions $\left(6 \mathrm{~J} \mathrm{~cm}^{-2}\right)$, we used two incubation periods: 2 and $16 \mathrm{~h}$. Irradiation was done using red LED at $630 \pm 10 \mathrm{~nm}$.

The results presented in Table 1 and Fig. 4 suggests that the structural modification performed in CHL-T improved the efficiency by 10 fold in both incubation times used. The $\mathrm{IC}_{50}$ of CHL-T after $2 \mathrm{~h}$ incubation is 15 fold lower than for HY. However, after $16 \mathrm{~h}$ of incubation, CHL-T was only about two times more cytotoxic than HY [22]. Previous studies in our group showed the same in other cell line and
Table 1

Mean inhibitory concentrations (IC ${ }_{50}$ ) for PSs incubated for $2 \mathrm{~h}$ and $16 \mathrm{~h}$. Cells were irradiated during $13 \mathrm{~min} 51 \mathrm{~s}$ with red light $(630 \pm 10 \mathrm{~nm})$ at dose of $6 \mathrm{~J} \mathrm{~cm}^{-2} ; 18 \mathrm{~mW} \mathrm{~cm}^{-2}$ and evaluated after $24 \mathrm{~h}, \mathrm{n}=3$.

\begin{tabular}{lll}
\hline & \multicolumn{2}{l}{$\mathrm{IC}_{50}(\mathrm{HEp}-2)[\mu \mathrm{M}]$} \\
\cline { 2 - 3 } & $2 \mathrm{~h}$ & $16 \mathrm{~h}$ \\
Incubation Time & & \\
CHL & $0.52 \pm 0.14$ & $0.34 \pm 0.19$ \\
CHL-T & $0.06 \pm 0.02$ & $0.03 \pm 0.01$ \\
HY & $0.72 \pm 0.16$ & $0.05 \pm 0.01$ \\
\hline
\end{tabular}

support that the period of $2 \mathrm{~h}$ is enough to chlorin derivatives to achieve lower $\mathrm{IC}_{50}$, while $\mathrm{HY}$ needs more time to accumulate and consequently to reducing its IC $_{50}[17]$.

In addition, we verified that the concentrations of the three PSs used showed no cytotoxicity in the absence of irradiation (data not shown).

\subsection{Determination of cell death type after photodynamic treatments}

\subsubsection{Fluorescence microscopy}

After PDT using the different PSs (incubation period of $2 \mathrm{~h}$ ), cells were labeled with ethidium bromide (EB) and acridine orange (AO) for detection of apoptosis (green nuclei with condensed chromatin) and necrosis (orange nuclei). A trained examiner counted a total of 200 cells in each well on a fluorescence microscope. The percentages of apoptotic and necrotic cells according to the experimental conditions are shown in Table 2. Percentage of live cells in the untreated controls, cells treated with PSs only without irradiation and cells irradiated but not exposed to the PSs were always greater than $80 \%$ (data not shown).

Increasing concentrations of all three PSs are associated with a corresponding increase in the percentage of cell death. It is noteworthy that the percentages of cell death achieved with CHL-T are only obtained with CHT or HY at concentrations approximately 10 times greater. These results indicate that the efficiency of the novel CHL-T is markedly superior in inducing cell death than CHL or HY.

Cell death (apoptosis and necrosis) was also assessed after a $16 \mathrm{~h}$ incubation with a concentration equivalent to $2 \times \mathrm{IC}_{50}$ (obtained for $2 \mathrm{~h}$ of incubation) of each PS (Table 3).

After $16 \mathrm{~h}$ of incubation with the tested PSs, the percentage of both apoptotic and necrotic cells was significantly higher for all PSs; however, this increase was noticeably greater for both chlorin derivatives (about 5-fold increase) in comparison with HY (about 2-fold increase).

The concentration of $0.52 \mu \mathrm{M}$ ( $\mathrm{IC}_{50}$ of $\mathrm{CHL}$ at $2 \mathrm{~h}$ of incubation) was chosen to compare the effect of the three PSs. Representative images of fluorescence microscopy are shown in Fig. 5.

The standardized concentration of $0.52 \mu \mathrm{M}$ was not cytotoxic for HY and CHL; in contrast to the noticeable cell death induced when CHL-T was used as the PS.

\subsubsection{Flow cytometry}

To confirm the induction of cell death by apoptosis or necrosis we used flow cytometry as an alternative experimental approach. These experiments were performed using standardized conditions: $0.52 \mu \mathrm{M}$ of
$\mathrm{CHL}$

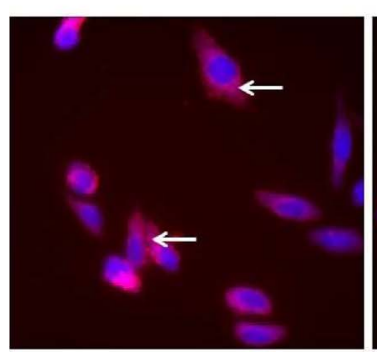

CHL-T

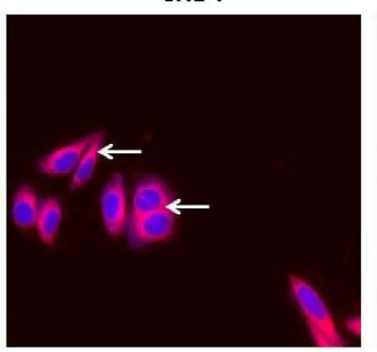

HY

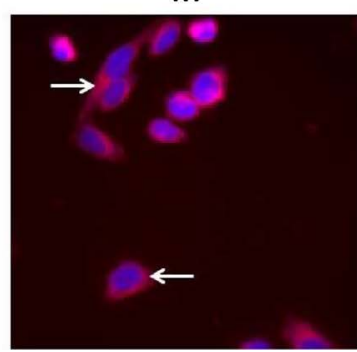

Fig. 3. Fluorescence microscopy image of HEp-2 cells simultaneously incubated with CHL (A), CHL-T (B) or HY (C) at $5 \mu \mathrm{M}$ during $1 \mathrm{~h}$ and DAPI (2,5\%). Overlays of the PSs fluorescence images(red) and nuclei stained with DAPI (blue). (For interpretation of the references to colour in this figure legend, the reader is referred to the web version of this article.) 


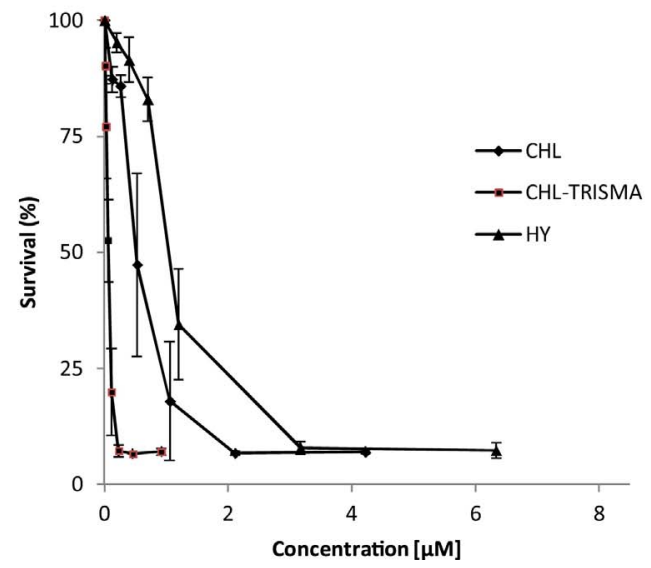

B

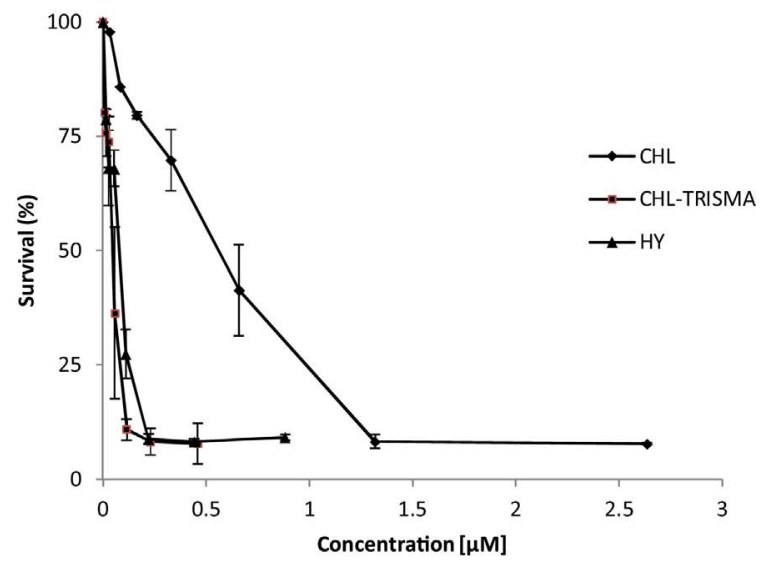

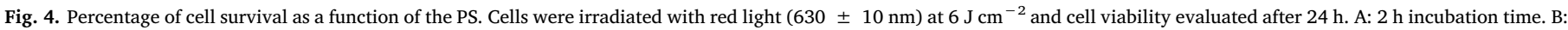
$16 \mathrm{~h}$ incubation time, $\mathrm{n}=3$. (For interpretation of the references to colour in this figure legend, the reader is referred to the web version of this article.)

Table 2

Percentages of cell death (apoptosis and necrosis) assessed by fluorescence microscopy in HEp- 2 cells labeled with ethidium bromide and acridine orange $24 \mathrm{~h}$ after photodynamic treatment using the three tested PSs at the indicated concentrations $(2 \mathrm{~h}$ incubation period, irradiation during $13 \mathrm{~min} 51 \mathrm{~s}$ with red light $-630 \pm 10 \mathrm{~nm}-$ at $6 \mathrm{~J} \mathrm{~cm}^{-2} ; 18 \mathrm{~mW} \mathrm{~cm}^{-2}$ ). * $\mathrm{p}<0.05$, ANOVA followed by Tukey, in comparison with untreated control cells, $\mathrm{n}=2$.

\begin{tabular}{llll}
\hline HEp-2 & & & \\
\hline PS & {$[P S](\mu \mathrm{M})$} & Apoptosis $(\%)$ & Necrosis (\%) \\
\hline CHL & 0.52 & $1.6 \pm 1.2$ & $1.0 \pm 0.6$ \\
CHL & 1.04 & $8.2 \pm 2.7$ & $5.7 \pm 1.1$ \\
CHL & 2.08 & $37.5^{*} \pm 6.4$ & $5.8 \pm 1.6$ \\
CHL & 8.49 & $22.2^{*} \pm 0.5$ & $69.3^{*} \pm 0.3$ \\
CHL-T & 0.06 & $1.1 \pm 0.1$ & $0.7 \pm 0.4$ \\
CHL-T & 0.12 & $5.1 \pm 1.1$ & $5.5 \pm 1.1$ \\
CHL-T & 0.24 & $9.7 \pm 0.1$ & $87.0^{*} \pm 15.9$ \\
CHL-T & 0.52 & $20.3^{*} \pm 4.5$ & $75.9^{*} \pm 6.1$ \\
CHL-T & 0.92 & $50.1^{*} \pm 5.2$ & $41.7^{*} \pm 5.3$ \\
HY & 0.52 & $5.1 \pm 0.4$ & $4.1 \pm 1.7$ \\
HY & 0.72 & $5.3 \pm 0.4$ & $4.4 \pm 0.7$ \\
HY & 1.44 & $8.1 \pm 2.8$ & $9.9 \pm 1.3$ \\
HY & 2.88 & $6.1 \pm 2.7$ & $85.8^{*} \pm 5.5$ \\
\hline
\end{tabular}

\section{Table 3}

Percentages of cell death (apoptosis and necrosis) assessed by fluorescence microscopy in HEp-2 cells labeled with ethidium bromide and acridine orange $24 \mathrm{~h}$ after photodynamic treatment with the three tested PSs at the indicated concentrations equivalent to $2 \times$ IC50 of CHL ( $16 \mathrm{~h}$ incubation period, irradiation at $630 \pm 10 \mathrm{~nm}$ with $6 \mathrm{~J} \mathrm{~cm}^{-2}$ ). ${ }^{*} \mathrm{p}<0.05$, ANOVA followed by Tukey, in comparison with untreated control cells, $\mathrm{n}=2$.

\begin{tabular}{llll}
\hline HEp-2 & & & \\
\hline PS & {$[\mathrm{PS}](\mu \mathrm{M})$} & Apoptosis (\%) & Necrosis (\%) \\
CHL & 1.04 & $31.3^{*} \pm 3.7$ & $30.4^{*} \pm 5.6$ \\
CHL-T & 0.12 & $28.6^{*} \pm 2.5$ & $20.7^{*} \pm 5.5$ \\
HY & 1.44 & $16.9^{*} \pm 2.8$ & $21.1^{*} \pm 7.7$ \\
\hline
\end{tabular}

PSs, $2 \mathrm{~h}$ of pre-incubation before the irradiation. Cells were evaluated $24 \mathrm{~h}$ after PDT. Controls included untreated cells, cells treated only with the PSs without irradiation, and cells irradiated but not exposed to any of the PSs. All controls had greater than $80 \%$ viable/live cells (data not shown).

To ensure that there was no interference from the fluorescence emitted by the PSs with that of the fluorophores FITC and PI used in the assay, cells treated with PSs only were analyzed. The results showed that the $0.52 \mu \mathrm{M}$ concentration of the PSs was not detected by the FL1 and FL2 photodetectors in the flow cytometer (data not shown).

Cells in the lower left quadrant are viable cells (FITC/PI-negative), in the lower right quadrant (FITC-positive/PI-negative) correspond to early apoptotic cells and in the right upper quadrant (FITC/PI-positive) the late apoptotic cells. Both CHL and HY did not reduce the percentage of viable cells, in contrast with the significant increase in early/late apoptotic cells observed with the use of CHL-T as the PS (Fig. 6).

\subsection{Evaluation of p53 protein expression by Western blot}

At the standardized concentration of $0.52 \mu \mathrm{M}$ of CHL and HY, PDT caused a discrete increase in the expression of pro-apoptotic p53 protein; whereas CHL-T at the same concentration caused a markedly greater increase in p53 protein (Fig. 7), which supports the findings of increased cell death associated with the use of CHL-T as the PS in the fluorescence microscopy and flow cytometry experiments.

\section{Discussion}

Our studies have shown that the CHL and CHL-T accumulate more in tumor cells than hypericin. It has been reported that increased intracellular accumulation may affect their cytotoxic effect [23,24]. Previous studies by our group show that chlorin derivatives (CHL and CHL-T) accumulate more than HY in HeLa cells $[17,22]$. In this study, we confirmed that CHL and CHL-T have a greater uptake than HY in the studied incubation periods in laryngeal carcinoma cells, and that CHL-T presents even greater intracellular accumulation than CHL. The increased accumulation of photosensitizer inside the cell is a relevant factor for the cytotoxic effect of PDT; however other factors need to be considered such as cell type, sub-cellular localization of PSs, and singlet oxygen generation $[25,26]$.

The localization of the three PSs studied in the cytoplasm was similar. It can be noticed that the distribution of PSs are homogeneous in the perinuclear space and did not distinguish for the three PSs. As the modification in the CHL structure to CHL-T increase its accumulation in HEp-2 cells and did not modify its localization, we conclude that the higher efficiency of CHL-T is due to the TRISMA group added, increasing its hydrophilicity and accumulation rate in the cells.

To compare the efficiency of cell death with PDT using CHL-T, we used a $2 \mathrm{~h}$ pre-incubation period, chosen because accumulation was similar for both CHL and CHL-T and also a $16 \mathrm{~h}$ pre-incubation period in which CHL-T intracellular accumulation markedly exceeded that of CHL. The irradiation conditions were also standardized. Results of the MTT assay demonstrate that the novel chemical modification performed in CHL improved its efficiency in inducing cell death by about 10 -fold after both used incubation periods. When comparing cytotoxicity of CHL-T with that of $\mathrm{HY}$, after the $2 \mathrm{~h}$ incubation the $\mathrm{IC}_{50}$ of $\mathrm{HY}$ 

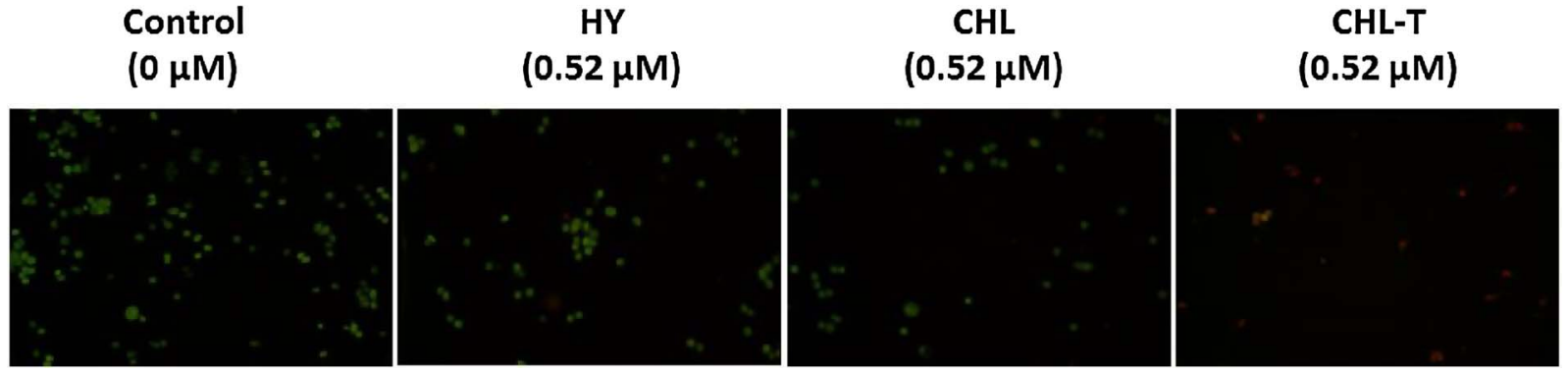

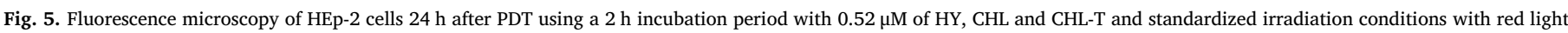

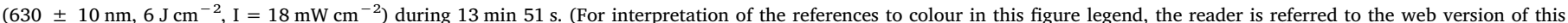
article.)

was about 15-fold greater than CHL-T; whereas after the $16 \mathrm{~h}$ of incubation the $\mathrm{IC}_{50}$ of $\mathrm{HY}$ was only twice compared to CHL-T. Our results, obtained by the MTT assay for the efficacy of HY as a PS is supported by a study using nasopharyngeal carcinoma cells incubated at a similar concentration $(0.05 \mu \mathrm{g} / \mathrm{mL}-0.09 \mu \mathrm{M})$ using $20 \mathrm{~h}$ of pre-incubation [27]. Similarly, the use of chlorin derivatives as PS in PDT is reported to have cytotoxic effect in other neoplasic cell lines, when used in longer preincubation and at a concentration of $0.5 \mu \mathrm{M}$, supporting our findings using CHL as the PS [28]. In breast tumor cells, with a 10-fold lower energy of irradiation $\left(0.63 \mathrm{~J} \mathrm{~cm}^{-2}\right)$ in comparison with that used in this study, the $\mathrm{IC}_{50}$ of CHL was approximately $60 \mu \mathrm{M}$ [29]. Collectively, these results indicate that the irradiation conditions play an important role in the efficacy of PDT; and also that the efficacy of PDT depends on the nature of the PS. An important aspect related with the nature of the PSs is the amphiphilicity, which affects its cellular uptake and intracellular localization [25]. Our results indicate that the novel structural amendment increased the amphiphilic characteristic of CHL and contributed to its increased cytotoxicity (CHL-T) when used as a PS in PDT treatments.

The cell death pathway activated, apoptosis or necrosis, is influenced by the concentration and subcellular localization of photosensitizer, irradiation conditions and cell type [26,30,31]. We determined the $\mathrm{IC}_{50}$ of each PS tested and used these concentrations to analyze the type of cell death by fluorescence microscopy. Our results indicated that in a fixed period of incubation $(2 \mathrm{~h})$ and standardized irradiation conditions higher concentrations of PS increased the proportion of cell death by necrosis. Interestingly, this trend was not consistent for the novel CHL-T, with increased cell death by apoptosis in higher concentration $(0.92 \mu \mathrm{M})$. This can be considered as a favorable result of this novel CHL-T, because with increasing concentration of this PS, there were more apoptotic cells, which is the desirable "clean" type of cell death.
A

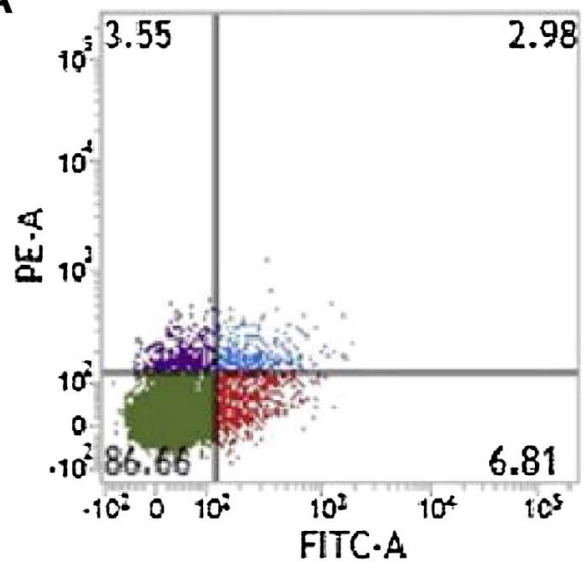

C

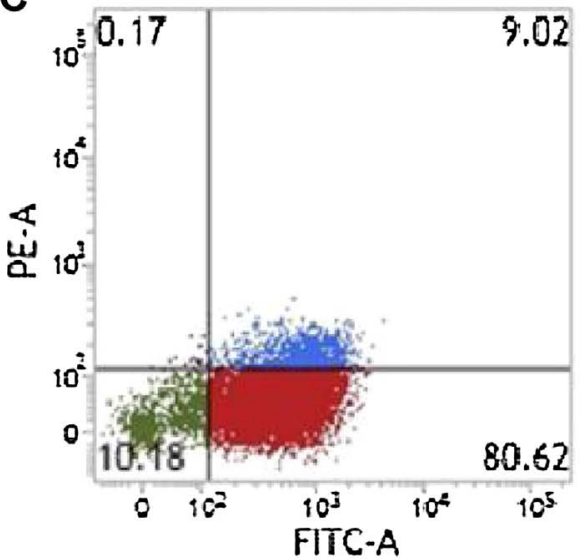

B

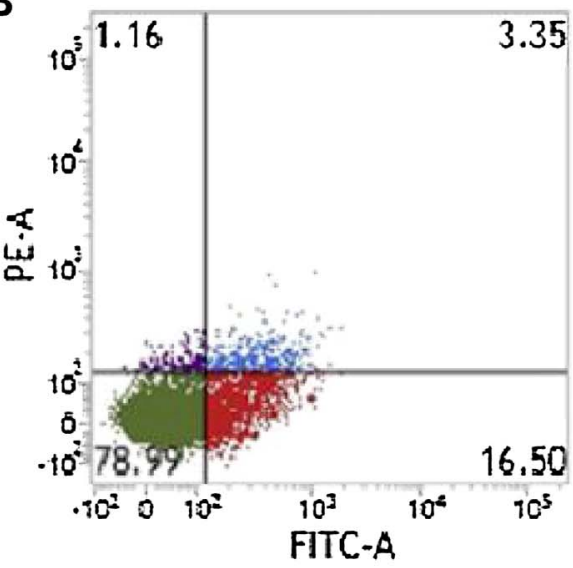

D

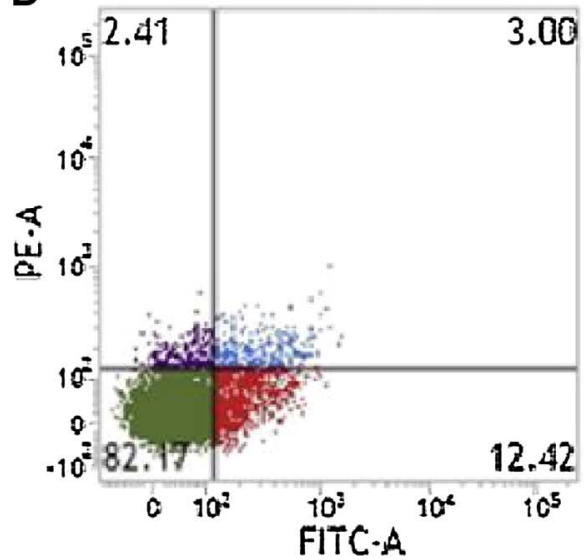

Fig. 6. Representative dot-blots of flow cytometry analysis of HEp- 2 cells using the Annexin V-FITC/PI assay $24 \mathrm{~h}$ after PDT using the indicated PSs under standardized irradiation conditions with red light $\left(630 \pm 10 \mathrm{~nm}, \quad 6 \mathrm{~J} \mathrm{~cm}^{-2} ; 18 \mathrm{~mW} \mathrm{~cm}^{-2}\right)$ during $13 \mathrm{~min} 51 \mathrm{~s}$. A: negative control. B: $0.52 \mu \mathrm{M}$ of $\mathrm{CHL}$. C: $0.52 \mu \mathrm{M}$ of CHL-T. D: $0.52 \mu \mathrm{M}$ of HY. The values presented in each quadrant represent the cell percentages. (For interpretation of the references to colour in this figure legend, the reader is referred to the web version of this article.) 


\section{B}

A

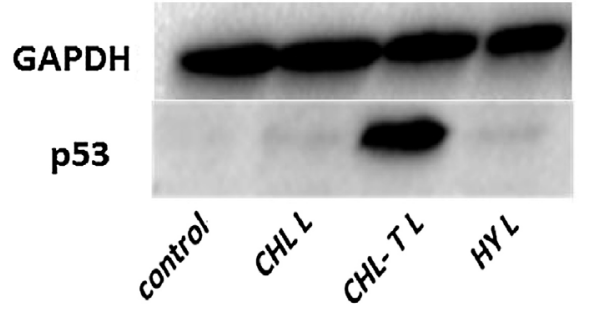

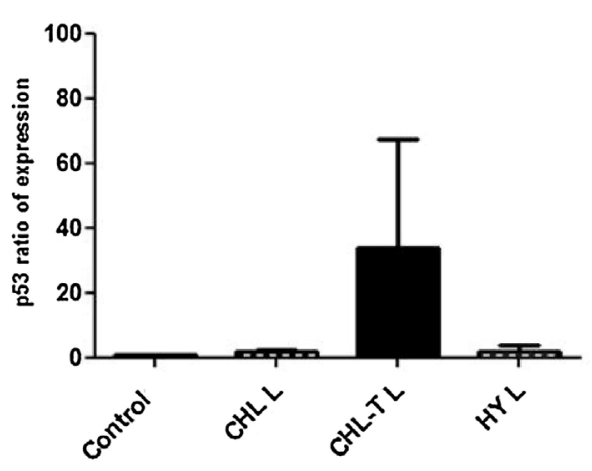

Fig. 7. (A) Representative image of western blot for p53 protein in HEp-2 cells $24 \mathrm{~h}$ after PDT using standardized concentration of the tested PSs $(0.52 \mu \mathrm{M})$ and standardized irradiation conditions with red light $\left(630 \pm 10 \mathrm{~nm}, 6 \mathrm{~J} \mathrm{~cm}^{-2} ; 18 \mathrm{~mW} \mathrm{~cm}^{-2}\right)$ during $13 \mathrm{~min}$ $51 \mathrm{~s}$. (B) Results of the semi-quantitative analysis by densitometry of the bands corresponding to $\mathrm{p} 53$ protein expression, normalized to the expression of GAPDH (Image $\mathrm{J}$ software), $\mathrm{n}=2$. (For interpretation of the references to colour in this figure legend, the reader is referred to the web version of this article.)
In multiple experimental settings using different photosensitizers and cell lines, apoptosis was found to be a prevalent cell death type in PDT [32]. Our data derived from flow cytometry analysis which has confirmed that CHL-T at $0.52 \mu \mathrm{M}$ markedly induces apoptosis in HEp-2 cells, whereas unmodified CHL and HY at the same concentration and irradiation conditions do not work similarly. The results of this experiment supports the findings of the other assays used in this study, demonstrating a greater potential of the novel CHL-T in inducing apoptosis of laryngeal cancer cells.

Cytotoxicity is usually measured by the mitochondrial enzyme activity (MTT assay) commonly interpreted as directly proportional and representative of cell viability and proliferation, however is an estimated colorimetric assay. According to Kepp et al., MTT-based assays are highly susceptible to metabolic interference, however these tests are very useful to obtain preliminary information and their results must be validated in secondary assays based on cell death markers [33]. Comparing the three methods used we expected different results. Despite the peculiarities of each method, it could be verified that CHL-T was the most cytotoxic PS compared to other two.

p53 is a tumor suppressor protein that rapidly responds to stress signals and can direct cells to mitochondria-mediated (intrinsic pathway) apoptosis [34,35]. Recently, over 3500 genes have been identified as targets of p53-mediated regulation, including genes associated with cell cycle control, DNA repair, apoptosis, metabolism and mRNA translation [36]. This protein is an important pro-apoptotic factor and several anti-tumor drugs target p53 activation as a therapeutic strategy. p53 activates other pro-apoptotic mediators such as Bax and DR-5 [37]. There is evidence indicating that p53 is involved in PDT-mediated cell death of human cells $[26,38]$. Importantly, a recent report associates increased p53 expression with the induction of apoptosis by a semi-synthetic analogue of a plant extract in HEp-2 cells [39]. We observed a clear and increase in p53 protein expression associated with PDT using the novel CHL-T as a PS, which correlated with the increased cytotoxicity and cell death by apoptosis using CHL-T. These results are supported by other studies, since the tumor death effects from PDT are associated with increased expression of p53; however the cytotoxic effects may also include p53-independent apoptosis $[40,41]$. Also, further studies will assess the biological role of this p53 increase for the enhanced apoptosis of HEp-2 cells subjected to PDT using CHL-T, as we cannot rule out that this increase in p53 expression is a feedback response to the apoptotic stimulus and not causally related with the outcome of apoptotic cell death. Even though the cytotoxic effects of PDT may not be exclusively dependent on p53 expression, there is a clear relationship between cell deaths induced by PDT effect and expression of p53. Our results demonstrate that the novel CHL-T used as PS enhances the cytotoxic effect of PDT in human laryngeal cancer cell line HEp-2.

\section{Conclusion}

Our experimental study demonstrates, for the first time, that the use of a new photosensitizer CHL-T strongly enhances the cytotoxic effect of PDT in HEp-2 cells. Moreover, the CHL-T presents increased intracellular accumulation and, at low concentrations this chemically modified chlorin strongly induces cell death predominantly by apoptosis, which is associated with increased expression of p53. Collectively, our results support a strong potential for this chemically-modified chlorin and should be further studied as a therapeutic approach for cancer treatment.

\section{Conflict of interest statement}

The authors declare that there are no conflicts of interest.

\section{Acknowledgements}

This study was supported by FAPESP (2015/21110-4, 2013/072761) and CNPq. The authors wish to thank Dr. Anderson O. Ribeiro of Federal University of $\mathrm{ABC}$ for the synthesis of hypericin, and CEPOFUSP for the Biotable used for irradiation of the cells. We also would like to thank Dr. Heloisa S. S. Araujo of UFSCar for the fluorescence images, using the ImageXpress ${ }^{\circ}$, Molecular Device (FAPESP- 2013//00798-2).

\section{References}

[1] J. Schuitmaker, P. Bass, H. vanLeengoed, F. vanderMeulen, W. Star, N. vanZandwijk, Photodynamic therapy: a promising new modality for the treat ment of cancer, J. Photochem. Photobiol. B -Biol. 34 (1) (1996) 3-12.

[2] S. Brown, E. Brown, I. Walker, The present and future role of photodynamic therapy in cancer treatment, Lancet Oncol. 58 (2004) 497-508.

[3] H. PASS, Photodynamic therapy in oncology - mechanisms and clinical use, J. Natl. Cancer Inst. 85 (6) (1993) 443-456.

[4] S. Bown, How mainstream medicine sees photodynamic therapy in the united kingdom, J. Natl. Compr. Canc. Netw. 10 (2012) S69-S74.

[5] J. Dabrowski, B. Pucelik, A. Regiel-Futyra, M. Brindell, O. Mazuryk, A. Kyziol, G. Stochel, W. Macyk, L. Arnaut, Engineering of relevant photodynamic processes through structural modifications of metallotetrapyrrolic photosensitizers, Coord. Chem. Rev. 325 (2016) 67-101

[6] R. Allison, C. Sibata, Oncologic photodynamic therapy photosensitizers: a clinical review, Photodiagn. Photodyn. Ther. 7 (2) (2010) 61-75.

[7] K. Plaetzer, B. Krammer, J. Berlanda, F. Berr, T. Kiesslich, Photophysics and photochemistry of photodynamic therapy: fundamental aspects, Lasers Med. Sci. 24 (2) (2009) 259-268.

[8] L. Moreira, M. Rodrigues, H. de Oliveira, A. Lima, R. Soares, V. Batistela, A. Gerola, N. Hioka, D. Severino, M. Baptista, A. Machado, Influence of different water-ethanol solvent systems on the spectroscopic and physicochemical properties of the macrocyclic compounds pheophytin and chlorophyll alpha, Quim. Nova 33 (2) (2010) $258-262$.

[9] A. Maestrin, C. Neri, K. de Oliveira, O. Serra, Y. Iamamoto, Extraction and purification of chlorophyll from spirulina maxima: an experiment for the chemistry courses, Quim. Nova 32 (6) (2009) 1670-1672.

[10] A. Uchoa, K. de Oliveira, M. Baptista, A. Bortoluzzi, Y. Iamamoto, O. Serra, Chlorin photosensitizers sterically designed to prevent self-aggregation, J. Org. Chem. 76 (21) (2011) 8824-8832.

[11] F. de Assis, J. de Souza, B. Assis, T. Brocksom, K. de Oliveira, Synthesis and 
photophysical studies of a chlorin sterically designed to prevent self-aggregation, Dyes Pigm. 98 (1) (2013) 153-159.

[12] F. dos Santos, A. Uchoa, M. Baptista, Y. Iamamoto, O. Serra, T. Brocksom, K. de Oliveira, Synthesis of functionalized chlorins sterically-prevented from self-aggregation, Dyes Pigm. 99 (2) (2013) 402-411.

[13] P. Agostinis, E. Buytaert, H. Breyssens, N. Hendrickx, Regulatory pathways in photodynamic therapy induced apoptosis, Photochem. Photobiol. Sci. 3 (8) (2004) 721-729.

[14] A. Vaseva, U. Moll, The mitochondrial p53 pathway, BBA-Bioenergetics 1787 (5) (2009) 414-420.

[15] A. Moor, Signaling pathways in cell death and survival after photodynamic therapy, J. Photochem. Photobiol. B-Biol. 57 (1) (2000) 1-13.

[16] E. Buytaert, M. Dewaele, P. Agostinis, Molecular effectors of multiple cell death pathways initiated by photodynamic therapy, Biochim. Et Biophys. Acta-Rev. Cancer 1776 (1) (2007) 86-107.

[17] M.N. Moritz, J.L. Gonçalves, I.A. Linares, J.R. Perussi, K.T. de Oliveira, Semisynthesis and pdt activities of a new amphiphilic chlorin derivative, Photodiagn. Photodyn. Ther. 17 (2017) 39-47.

[18] H. Falk, J. Meyer, M. Oberreiter, A convenient semisynthetic route to hypericin, Monatsh. Chem. 124 (3) (1993) 339-341.

[19] O. Lowry, N. Rosebrough, A. Farr, R. Randall, Protein measurement with the folin phenol reagent, J. Biol. Chem. 193 (1) (1951) 365-375.

[20] T.C. Chou, M. Hayball, Calcusyn Windows Software for Dose Effect Analysis, Biosoft, Cambridge, 1996.

[21] A. Mcgahon, S. Martin, R. Bissonnette, A. MahboubI, Y. Shi, R. Mogil, W. Nishioka, D. Green, The end of the (cell) line - methods for the study of apoptosis in-vitro, Methods Cell Biol. 46 (1995) 153-185.

[22] C. Bernal, A.O. Ribeiro, J.R. Perrusi, Photodynamic efficiency of hypericin compared with a chlorine and hematoporphyrin derivative in hep-2 and vero epithelial cell lines, Photodiagn. Photodyn. Ther. 12 (2) (2015) 176-185.

[23] T. Vuong, C. Vever-Bizet, S. Bonneau, G. Bourg-Heckly, Hypericin incorporation and localization in fixed hela cells for various conditions of fixation and incubation, Photochem. Photobiol. Sci. 10 (4) (2011) 561-568.

[24] T. Kiesslich, D. Neureiter, B. Alinger, G. Jansky, J. Berlanda, V. Mkrtchyan, M. Ocker, K. Plaetzer, F. Berr, Uptake and phototoxicity of meso-tetrahydroxyphenyl chlorine are highly variable in human biliary tract cancer cell lines and correlate with markers of differentiation and proliferation, Photochem. Photobiol. Sci. 9 (5) (2010) 734-743.

[25] A. Uzdensky, O. Dergacheva, A. Zhavoronkova, A. Reshetnikov, G. Ponomarev, Photodynamic effect of novel chlorin e(6) derivatives on a single nerve cell, Life Sci. 74 (17) (2004) 2185-2197.

[26] R. Almeida, B. Manadas, A. Carvalho, C. Duarte, Intracellular signaling mechanisms in photodynamic therapy, Biochim. Et Biophys. Acta-Rev. Cancer 1704 (2) (2004) 59-86.
[27] X. Wang, Y. Guo, S. Yang, C. Wang, X. Fu, J. Wang, Y. Mao, J. Zhang, Y. Li, Cellular and molecular mechanisms of photodynamic hypericin therapy for nasopharyngeal carcinoma cells, J. Pharmacol. Exp. Ther. 334 (3) (2010) 847-853.

[28] I. Sheyhedin, K. Aizawa, M. Araake, H. Kumasaka, T. Okunaka, H. Kato, The effects of serum on cellular uptake and phototoxicity of mono-l-aspartyl chlorin e6 (npe6) in vitro, Photochem. Photobiol. 68 (1) (1998) 110-114.

[29] J. Dabrowski, L. Arnaut, M. Pereira, C. Monteiro, K. Urbanska, S. Simoes, G. Stochel, New halogenated water-soluble chlorin and bacteriochlorin as photostable PDT sensitizers: synthesis, spectroscopy, photophysics, and in vitro photosensitizing efficacy, Chemmedchem 5 (10) (2010) 1770-1780.

[30] M. Varnes, S. Chiu, L. Xue, N. Oleinick, Photodynamic therapy-induced apoptosis in lymphoma cells: translocation of cytochrome c causes inhibition of respiration as well as caspase activation, Biochem. Biophys. Res. Commun. 255 (3) (1999) 673-679.

[31] S. Chiu, N. Oleinick, Dissociation of mitochondrial depolarization from cytochrome c release during apoptosis induced by photodynamic therapy, Br. J. Cancer 84 (8) (2001) 1099-1106.

[32] N. Oleinick, R. Morris, T. Belichenko, The role of apoptosis in response to photodynamic therapy: what, where, why, and how, Photochem. Photobiol. Sci. 1 (1) (2002) 1-21.

[33] O. Kepp, L. Galluzzi, M. Lipinski, J. Yuan, G. Kroemer, Cell death assays for drug discovery, Nat. Rev. Drug Discov. 10 (3) (2011) 221-237.

[34] G. Sorrentino, M. Mioni, C. Giorgi, N. Ruggeri, P. Pinton, U. Moll, F. Mantovani, G. Del Sal, The prolyl-isomerase pin1 activates the mitochondrial death program of p53, Cell Death Differ. 20 (2) (2013) 198-208.

[35] M. Kastan, O. Onyekwere, D. Sidransky, B. Vogelstein, R. Craig, Participation of p53 protein in the cellular-response to dna damage, Cancer Res. 51 (23) (1991) 6304-6311.

[36] M. Fischer, Census and evaluation of p53 target genes, Oncogene (2017).

[37] S. Benchimol, P53-dependent pathways of apoptosis, Cell Death Differ. 8 (11) (2001) 1049-1051.

[38] Z. Tong, G. Singh, A. Rainbow, The role of the p53 tumor suppressor in the response of human cells to photofrin-mediated photodynamic therapy, Photochem. Photobiol. 71 (2) (2000) 201-210.

[39] Y.Y. Han, J.J. Tang, R.F. Gao, X. Guo, M. Lei, J.M. Gao, A new semisynthetic 1-oacetyl-6-o-lauroylbritannilactone induces apoptosis of human laryngocarcinoma cells through p53-dependent pathway, Toxicol. In Vitro 35 (2016) 112-120.

[40] D. Nowis, M. Makowski, T. Stoklosa, M. Legat, T. Issat, J. Golab, Direct tumor damage mechanisms of photodynamic therapy, Acta Biochim. Pol. 52 (2) (2005) 339-352.

[41] A. Hajri, S. Wack, C. Meyer, M. Smith, C. Leberquier, M. Kedinger, M. Aprahamian, In vitro and in vivo efficacy of photofrin ( $\mathrm{r}$ ) and pheophorbide $\mathrm{a}$, a bacteriochlorin, in photodynamic therapy of colonic cancer cells, Photochem. Photobiol. 75 (2) (2002) 140-148. 